\title{
Access to Biobanks: Harmonization Across Biobank Initiatives
}

\author{
Michiel Verlinden, ${ }^{1}$ Herman Nys, ${ }^{2}$ Nadine Ectors, ${ }^{3,4}$ and Isabelle Huys ${ }^{1,5}$
}

Purpose: The current study investigates whether access arrangements relevant for biobanking contain clear information on key access conditions. It furthermore assesses the extent to which these access conditions are harmonized across biobank initiatives.

Methods: A comparative analysis was conducted of access arrangements developed by 26 organizations, 36 biobank networks, and 20 biobanks worldwide.

Results: The study demonstrates a lack of clear information on 21 key access conditions relevant for biobanking. Furthermore, it confirms that the harmonization across biobank initiatives is limited.

Conclusion: Many biobank initiatives need to be more transparent on how they apply the studied access conditions.

\section{Introduction}

A CCESS TO HUMAN BIOLOGICAL MATERIALS (HBMs) and associated data stored in biobanks is crucial for biomedical research. ${ }^{1-3}$ Researchers need to be able to access different collections of HBMs and data efficiently. ${ }^{4-6}$ In order to guarantee their long-time sustainability as well as the scientific, legal, and ethical correct use of HBMs and data, biobanks and biobank networks need to exercise control on the access to their resources. ${ }^{1,2,4,5,7,8}$ Taking into account the above, it is not surprising that several organizations and authors have stressed the importance of clear and transparent rules on access. $2,4,5,9-17$

Previous empirical studies focused on guidelines and policies in relation to (among others) governance, consent, and return of incidental findings. ${ }^{18-23}$ Only a few empirical studies have focused on access arrangements, ${ }^{2,4,5,11-13}$ such as guidelines, best practices, opinions, policies, agreements, etc. containing rules on access to and use of HBM and data collections stored within biobanks (a similar definition of access arrangements is used by Fortin et al. ${ }^{2}$ and the $\left.\mathrm{OECD}^{24}\right)$.

The current study provides qualitative data on the extent to which access arrangements contain information on 21 selected key access conditions and the level of harmonization of these conditions.

\section{Materials and Methods}

\section{Definitions}

In this article, the term 'organizations' refers to 'organizations and associations not directly involved in the management of a biobank or biobank network, but active in the development of guidelines, policies, or best practices pertaining to access to HBMs or data or both.' The term 'biobank' refers to 'a (single) infrastructure dedicated to the storage and provision of HBMs or data or both for research purposes.' The term 'biobank network' refers to 'a group of institutions who freely assume the commitment to collaborate in the domain of biobanking and who (often) share the same procedures and quality policies, and who are (or might be) helped by a central hub for coordination in terms of service'. The term 'biobank initiatives' covers biobanks, biobank networks, as well as organizations. 'Basic HBMs' can be defined as 'HBMs that have not been subjected to processing or any other manipulation, except for the purpose of storing the HBM or providing it to an applicant.' 'Basic data' is defined as 'data that has not been subjected to analysis or any other processing, except for the purpose of storing the data or providing it to an applicant.' Custodianship can be defined as the "caretaking responsibility for HBM and data that starts at the planning of a biobank initiative, prior to the collection, and continues through

\footnotetext{
${ }^{1}$ Clinical Pharmacology and Pharmacotherapy, KU Leuven, Belgium.

${ }^{2}$ Interfaculty Centre for Biomedical Ethics and Law, KU Leuven, Belgium.

${ }^{3}$ AC Biobanking, UZ Leuven, Belgium.

${ }^{4}$ Translational Cell and Tissue Research, KU Leuven, Belgium.

${ }^{5}$ Centre for Intellectual Property Rights, KU Leuven, Belgium.
} 
research use to final dissemination of research results' (a slightly adapted version of the definition used by R. Yassin et al. $^{25}$ and the National Cancer Institute ${ }^{26}$ ).

\section{Document selection and collection}

Twenty-seven international, regional, and national organizations in the European Union, the United States, Canada and Australia were identified (see Supplementary Table S2; supplementary material is available online at www.liebertpub .com/bio). In addition, a literature review on access to HBMs or data, supplemented with information from the Public Population Project in Genomics and Society $\left(\mathrm{P}^{3} \mathrm{G}\right)$, the Biobanking and Biomolecular Resources Research Infrastructure (BBMRI.ERIC), the Deutscher Ethikrat, and the Institute for Prospective Technological Studies (IPTS) of the European Commission's Joint Research Centre (JRC), served as a basis to develop an overview of 51 biobank networks and 22 biobanks worldwide (see Supplementary Table S1 available in the online article at www.liebertpub.com/bio). ${ }^{14,27-30}$ The majority of the identified biobank initiatives were established and funded by not-for-profit institutions. Limited information was found for biobanks funded by for-profit institutions. The comparative study focused on access to HBMs or data or both for purposes of biomedical research.

\section{Access to publicly available access arrangements}

Websites and (scientific) publications available in English, French, Dutch, German, or Spanish were reviewed in order to retrieve publicly available access arrangements of the selected biobank initiatives. In case no access arrangement was found, the contact person of the biobank initiative was contacted via e-mail with the question of whether it had developed an access arrangement and could provide a copy of such arrangement. In the absence of a response, one reminder was sent.

\section{Identification of key access conditions for biobanking}

In a preparatory phase, international literature in relation to access to HBMs or data was reviewed using online resources (PubMed, Embase and Web of Science). The terms 'biological specimen bank,' 'biobanking,' 'biobank,' 'biological repository,' and 'research' were used to review these resources. The literature ${ }^{2,10,12,14,21,31-33}$ was supplemented with information found on the website of $\mathrm{P}^{3} \mathrm{G}^{14,27}$ and a report drafted at the request of the Medical Research Council and The Wellcome Trust. ${ }^{4}$ This allowed us to identify 21 key conditions in relation to access to HBMs and data (Table 1). It was decided not to focus on consent, since this has been investigated extensively in previous studies. ${ }^{4,8,12,18-21}$

\section{Comparative analysis of access arrangements}

In the second phase (August 2011 and January 2013, at which time two extra copies of access arrangements were obtained), a comparative analysis was conducted of the access arrangements. Although access arrangements of organizations, biobank networks, and biobanks may not be entirely comparable, taking into account their different characteristics and purposes, access arrangements for each category of biobank initiatives influence the question of whether access conditions are harmonized. We therefore studied the access arrangements of all three categories of biobank initiatives, investigating the trends and differences within as well as between each category, and addressing the question whether access arrangements promulgated by organizations influence those of biobank networks and individual biobanks. First it was investigated to what extent each of those arrangements contained information in relation to the $21 \mathrm{key}$ access conditions identified in the literature review. ${ }^{2,4,11-14,27}$ If available, the information on the key conditions was summarized and compared using predefined templates. When access arrangements did not explicitly refer to one or more of the 21 access conditions under study, the text of the arrangement was interpreted to discover implicit information on such conditions. It cannot be excluded that some of these interpretations might not fully correspond with the real (unexpressed) intentions of the concerned biobank initiative. The comparative templates allowed us to develop qualitative data illustrating the lack of clear information and harmonization in relation to the 21 selected access conditions (see Supplementary Table S2). Finally, we investigated to what extent access arrangements of biobank initiatives applied the 21 selected access conditions differently, depending on whether these initiatives were (rather) population- or hospital-integrated.

\section{Results}

We retrieved the access arrangements for 26 organizations, 36 biobank networks, and 20 biobanks. We were not able to obtain access arrangements for one organization, 15 biobank networks, and 2 biobanks. Of those that we were not able to obtain, thirteen access arrangements were not publicly available, and three were under development (thus also unavailable). One organization and one biobank did not yet develop an access arrangement. We discovered relatively few differences in how access arrangements of population- and hospital-integrated biobank initiatives were applied to the 21 key access conditions. Therefore we decided not to focus on the distinction between those types.

\section{Lack of clear information}

An important number of access arrangements do not contain (clear) information on how the concerned biobank initiatives define the 21 access conditions investigated in the current study. Hereafter, the results concerning six selected conditions are described in detail that, according to our analysis, represent the most remarkable findings. An overview of all the results of the comparative analysis can be found in the Supplementary Table S2.

\section{Ownership}

None of the access arrangements provided that the principal investigators became the owner of basic HBMs and/or data that they collected and provided to the biobank initiative.

The majority of the access arrangements that provided access to HBM (14 organizations, 22 biobank networks, and 13 biobanks) did not stipulate whether the biobank network, the biobank, or the principal investigator held ownership rights in relation to the basic HBMs (Fig. 1). 
Table 1. Overview of Access Conditions

1. Access to data and/or HBM

2. Type of HBM

3. Type of data

4 \& 5. Level of ownership of primary HBM and data

$6 \& 7$. Level of custodianship of HBM and data

8. Access committees

9. Mandate access committee

10. Screening of scientific merit

11. Access by industrial company

12 \& 13. External/industrial applications: Different legal conditions and fees

14. Priority setting

15. Intellectual property

16. Exclusive (access) right of applicant

17. Preferential (access) right of collector

18. Benefit sharing

19. Sharing or returning research data or results

20. Data protection

21. Return and/or destruction of tissue
Does the access arrangement apply to data, HBM or both?

To which type of HBM does the access arrangement apply?

To which type of data does the access arrangement apply?

Which level (biobank network, biobank or PI) holds ownership over primary HBM and primary data?

Which level (biobank network, biobank, funder or PI) holds custodianship over HBM and data?

To which extent does the access arrangement provide for a committee to decide on access to HBM, data or both?

How is the mandate of the access committee specified in the access arrangement?

Does the access arrangement provide for a screening of the scientific merit of access requests and how?

What does the access arrangement provide in relation to access by industrial companies to the HBM and/or data?

To which extent does the access arrangement provide different legal conditions and fees for external or industrial applications compared to internal applications?

Does the access arrangement provide criteria to prioritize parallel applications and if this would be the case, which criteria are stipulated?

What does the access arrangement provide in relation to IP rights held by the biobank?

To which extent does the access arrangement provide the applicants exclusive access to certain HBM and data?

To which extent does the access arrangement provide preferential (access) to collectors who provided HBM and data to the biobank initiative?

To which extent does the access arrangement stipulate an obligation to share benefits resulting from the use of HBM and/or data?

To which extent does the access arrangement stipulate an obligation to return to the biobank initiative or share with third parties research data or results?

To which extent does the access arrangement provide access to coded, anonymised or identifiable data?

To which extent does the access arrangement stipulate an obligation to return and/or destroy leftover tissue?

These conditions were considered key to access, considering the high number of times they were mentioned in scientific literature and in access arrangements.

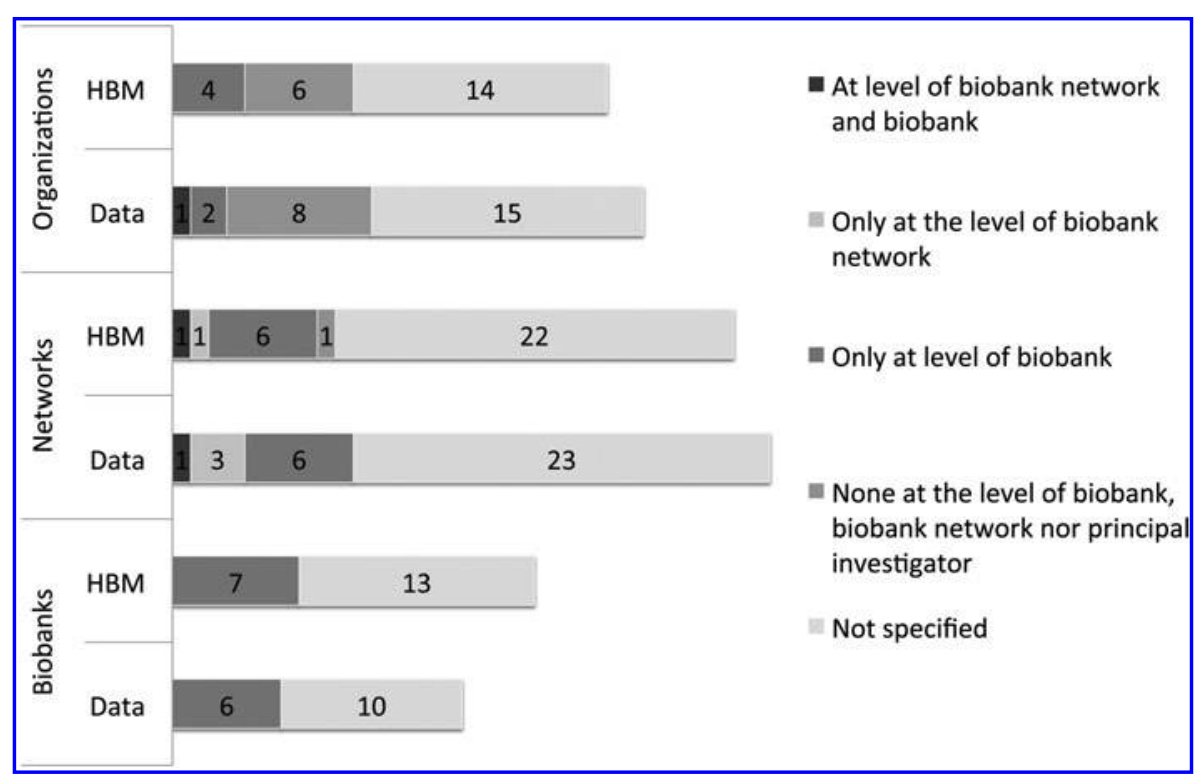

FIG. 1. Number of access arrangements of organizations, biobank networks, and biobanks that provide ownership of HBM and data at the level of the biobank network, the biobank, or both. 
The majority of the access arrangements that provided for access to data (15 organizations, 23 biobank networks, and 10 biobanks) did not stipulate whether the biobank network, the biobank, or the principal investigator held ownership rights in relation to the basic data (Fig. 1).

Access arrangements of 8 organizations (where 5 are organizations from the United Kingdom) explicitly provide that neither the biobank network, nor the biobank, nor the principal investigator hold ownership in relation to basic data (as such).

\section{Level of custodianship}

The level of custodianship over HBMs was not defined in the access arrangements of 11 organizations, 6 biobank networks, and 4 biobanks.

With respect to biobank networks, 6 out of 31 access arrangements stipulated that the biobank network held (exclusive) custodianship over HBMs, while 15 stipulated that custodianship was held only at the level of the biobank (Fig. 2 ), and 4 stipulated that the biobank network and the biobank shared custodianship.

The access arrangement of one biobank provided for shared custodianship over HBMs between the biobank and the principal investigator, while the access arrangements of 14 biobanks granted custodianship to the biobank; the access arrangement of one biobank stipulated that the principal investigator held custodianship over the samples collected by him/her.

The level of custodianship over data was not defined in access arrangements of 16 organizations, 6 biobank networks, and 3 biobanks.

With respect to biobank networks, 10 access arrangements stipulated that custodianship was held only at the level of the biobank network, while access arrangements of 11 biobank networks stipulated that custodianship was held only at the level of the biobank. Access arrangements of 4 biobank networks provided that the biobank network and the biobank shared custodianship over the data.

The results revealed an evolving trend to provide custodianship to the biobank or biobank network and no longer to principal investigators. The comparative analysis did not provide an unambiguous answer to the question of whether there is a tendency within biobank networks to provide custodianship at the level of the biobank network instead of the biobank.

\section{Scope of custodianship}

The comparative analysis revealed differences in how access arrangements defined custodianship. The following (common) elements were identified on the basis of the comparison: (i) the responsibility to safeguard the confidentiality, integrity, and security of the collection and the interests of the donors. Custodianship could furthermore consist of (ii) the right to control the preservation, access, use, transfer, and/or disposal of collections.

\section{Access committees}

The majority of the screened access arrangements (14 organizations, 23 biobank networks and 14 biobanks; see Supplementary Table S2) established an access committee. One organization and one biobank network stipulated explicitly that no access committee was established.

When we looked specifically at access arrangements that involved establishing an access committee, we noticed that access committees of 11 organizations, 16 biobank networks, and 12 biobanks provided advice or decided on each request for access (Fig. 3).

\section{Screening of scientific merits}

The comparative analysis revealed that only half of the access arrangements (access arrangements of 11 organizations, 18 biobank networks, and 11 biobanks (Fig. 4)) stipulate explicitly whether the scientific merit of access requests is screened. One organization's access arrangement stated explicitly that it did not screen the scientific merits, since it did not feel competent to conduct such screening. Access arrangements of 8 organizations explicitly provided extensive scientific screening, while only 4 biobanks and no biobank networks provided such extensive screening.
FIG. 2. Number of access arrangements of organizations, biobank networks, and biobanks that provide custodianship of HBM and data at the level of the biobank network, the biobank, the funder, the principal investigator, or a combination of those different actors.

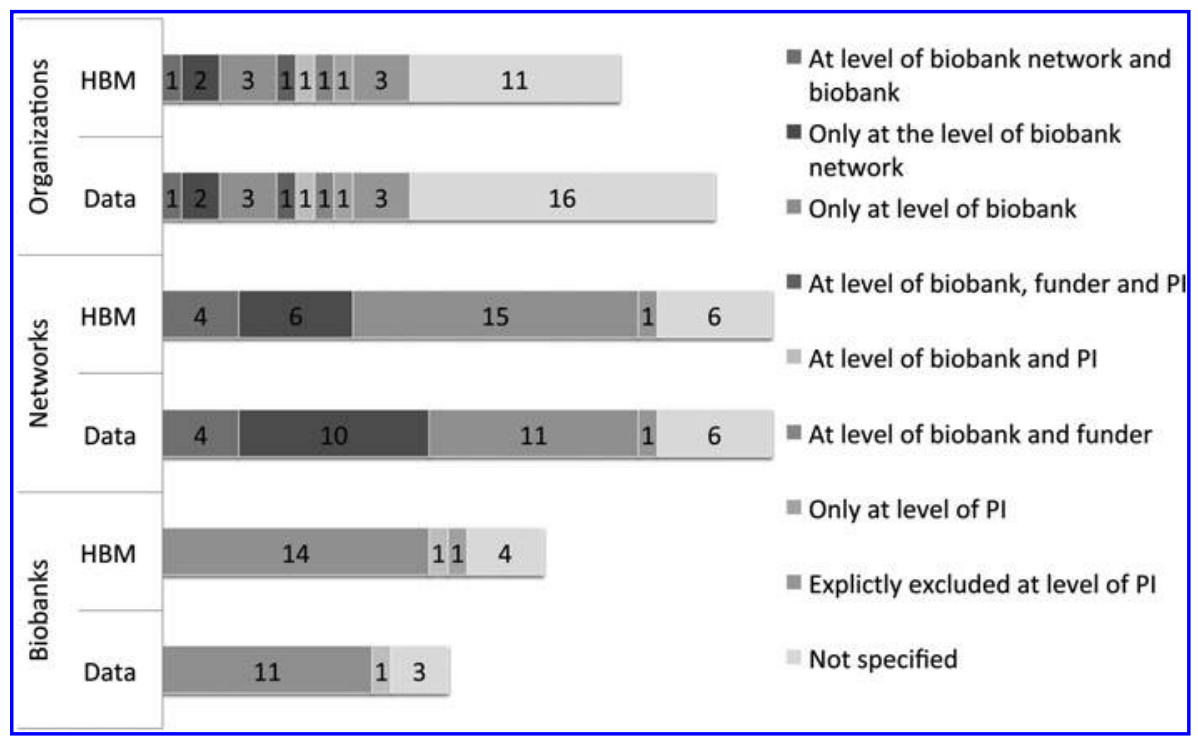




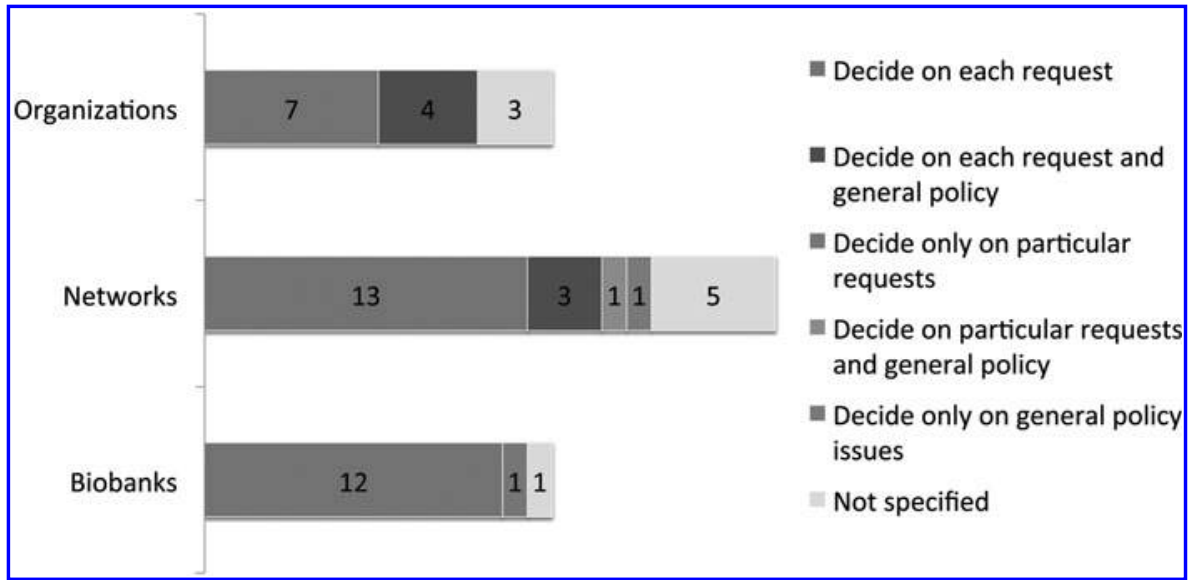

FIG. 3. Number of access arrangements of organizations, biobank networks, and biobanks that define the mandate of access committees and the number of access committees that provided a mandate to decide on each request for access (and/or general policy issues), on particular (but not each) request for access (and/or general policy issues), or only on (general) policy issues.

\section{Sharing or returning of research results}

Access arrangements of 14 organizations, 17 biobank networks, and 15 biobanks (Fig. 5) stipulated explicitly the obligation to share and/or return research data or results. When focusing on biobanks considered as population-based, 9 out of 10 access arrangements provide for an obligation to share or return research data or results.

\section{Discussion}

The comparative analysis provides empirical data on 21 selected conditions characterizing access arrangements for biobanks. It covers access arrangements developed by 26 organizations, 36 biobank networks, and 20 biobanks worldwide (see Supplementary Table S1 available in the online article at www.liebertpub.com/bio). Since we did not find evidence of trends or differences that specifically pertain to one of the categories of biobank initiatives, we discuss trends and differences in access arrangements for the three categories together, without distinguishing between them. Previous empirical studies on access arrangements tended to focus on a limited number of access conditions or studied a limited number of access arrangements. $4,5,11-14,27$

\section{Lack of clear information}

An important number of access arrangements do not contain clear information on how the concerned biobank initiatives define several of the 21 access conditions investigated in the current study. Such a lack of information constitutes an important barrier for researchers who apply for access to biobanks. ${ }^{1,2,4,5,11-13,16,34}$

\section{Ownership or custodianship}

The study revealed that the majority of the access arrangements do not stipulate anything in relation to ownership of HBM (and associated data). This is probably due to the fact that it remains uncertain which 'ownership' rights can be held or claimed in relation to HBMs. $1,4,15,16,19,35$ Opinions in scientific literature differ on whether such rights can be held by the donor, the collector of HBM, the researcher using the HBM, or a biobank. $1,8,34-37$

Taking into account the uncertain status of 'ownership' on HBM, we suggest focusing instead on the (bundle/compilation of) rights held by the custodian HBM or data-irrespective of the question whether such rights could be considered as 'ownership' rights. ${ }^{25}$ Björkman pointed out that rights on HBMs could be constructed in many different ways depending on the legal relations included in the bundle of rights. She rightfully argued that the most important question concerns the determination of the rights to be included in such bundle. The question of whether such a bundle of rights would constitute ownership is of minor importance. ${ }^{38}$

It appeared from the comparative analysis that access arrangements contain different definitions of the rights

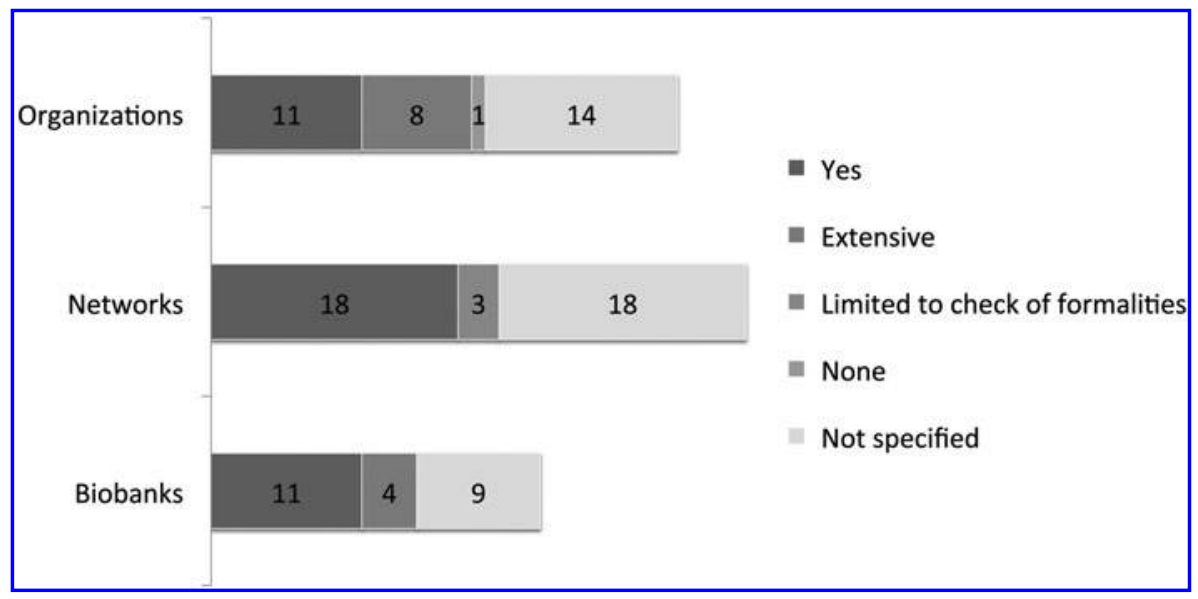

FIG. 4. Number of access arrangements of organizations, biobank networks, and biobanks that provide for a scientific screening of access requests and whether an extensive or limited screening is provided. 
FIG. 5. Number of access arrangements of organizations, biobank networks, and biobanks that require the return to the biobank initiative and/or the sharing with the scientific community of research results.

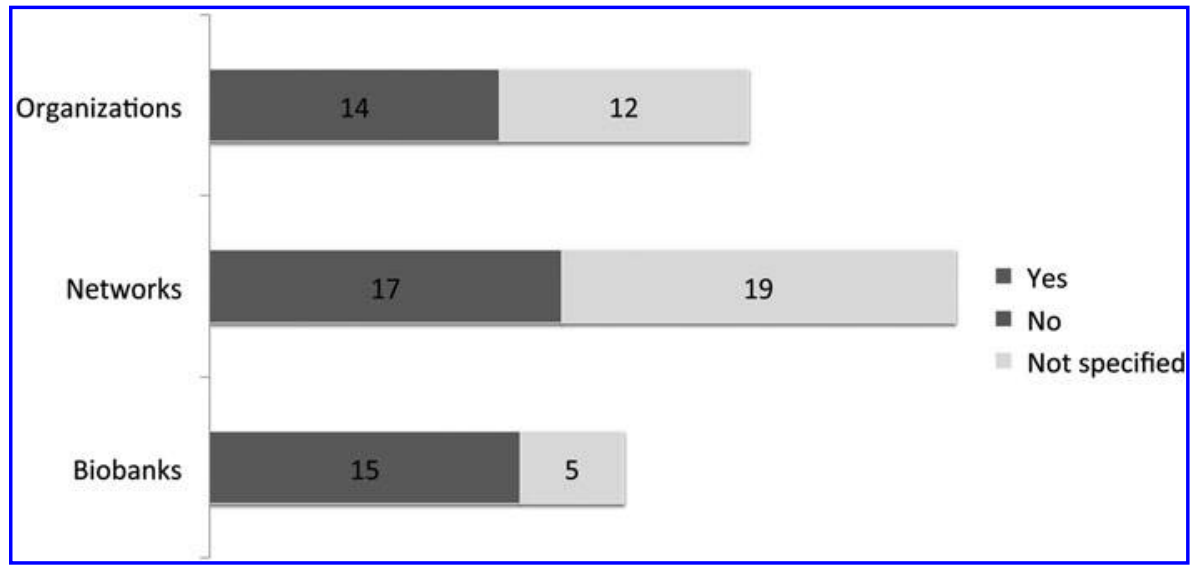

and obligations of custodians. Therefore, it remainsunfortunately_difficult for an applicant to know which rights a custodian holds over a collection of HBMs and data.

\section{Level of custodianship: Biobank vs. principal investigator}

The evolution in the trend to provide custodianship to a biobank or a biobank network is presumably due to the fact that biobanks increasingly store high numbers of HBMs and/or data, which cannot be managed in an optimal manner by an individual researcher/collector. ${ }^{11,19,20,34}$ Custodianship at the level of the biobank or biobank network can facilitate access to HBM and data, since it is no longer necessary to obtain approval of each individual researcher or collector.

\section{Level of custodianship of HBM: Biobank network vs. biobank}

Some of the studied access arrangements provide custodianship at the level of the biobank network, while the majority provides custodianship at the level of the biobank. The different approaches might be due to the fact that some collections were created specifically in the framework of a biobank network. In this case, the participating biobanks might be more willing to allow the biobank network to exercise custodianship. In other networks, the individual biobanks created collections outside the network and subsequently decided to share those collections in the framework of the biobank network. In this case, the individual biobanks might want to maintain the possibility to decide on access to 'their' HBMs and/or data. Both approaches can be defended, but an applicant needs be clearly informed on whether the biobank network or the biobank decides on access to samples and data.

\section{Level of custodianship: Data vs. HBM}

The comparison demonstrated that custodianship of data (in contrast to custodianship of samples) is more often held at the level of the biobank network. This might be explained by the fact that different researchers can access data simultaneously. Since the biobank maintains the possibility to access and use its 'own' data, it might be more comfortable allowing the biobank network to decide which researchers can access the data shared in the network. The sharing of data could be facilitated by the fact that biobank networks decide on access to data and an applicant, therefore, needs to obtain authorization from fewer biobank initiatives.

\section{Access committees}

When biobank initiatives claim custodianship over HBM or data, they have the responsibility to develop transparent access arrangements and to establish access committees to decide on access requests. Such access committees need to ensure that HBM and data are used in accordance with the initial consent. They furthermore verify that the HBM is only used for research projects that demonstrate sufficient scientific merits. It is therefore no surprise that the comparative analysis confirmed that the majority of the access arrangements establish an access committee.

\section{Screening of scientific merit and relevance}

Only half of the studied access arrangements stipulate explicitly whether the scientific merit of access requests is screened. This is unfortunate, since applicants need to have clear information on such screening. Screening the scientific merits of applications can ensure that HBMs and data are not wasted. ${ }^{2}$ This is even more the case in relation to rare HBMs. ${ }^{11,39}$ Finally, the biobank initiative might want to verify whether the proposed use of HBMs and data corresponds with the scientific aims of the collection. ${ }^{11}$

Some biobank initiatives might not explicitly provide for the screening of the scientific merit of access requests, since they are of the opinion that such screening is the responsibility of an ethics review board or the organization funding the research project. ${ }^{4}$ Furthermore, access committees of biobank initiatives might not always have the capacity and/ or specialization to screen the scientific merit of each application; especially in view of the wide range of disciplines of applicant researchers. We recommend that clear information is provided to applicants on whether and how the scientific merit of their access requests is screened.

\section{Obligation to share or return research results}

The majority of the access arrangements require the returning and/or sharing of research results with the biobank or other researchers. This might be due to the fact that an increasing number of funding bodies require such sharing or returning of research results. Furthermore, this could be justified by the substantial (public) investment required to 
collect, store, and manage in HBM and data in an optimal manner. However, the sharing or returning of research results is only useful when the necessary capacity is available to store, correctly interpret, and access the results.

Since researchers invest a considerable amount of time and effort in generating research results or data, they could be allowed, during a limited period of time, the exclusive right to decide who has access to them.

\section{Conclusion}

Several authors active in the biobank field have pointed out that an increased harmonization of access conditions could facilitate access to biobanks. ${ }^{1,2,5,8,10,20,21,27.40}$ Since many access arrangements do not contain clear information in relation to several of these conditions, it is difficult to draw final conclusions on the extent of harmonization. The comparative analysis demonstrated a lack of harmonization of access arrangements in relation to the majority of the 21 examined access conditions. It furthermore underlines that biobank initiatives should increase their efforts to provide clear information on their access conditions. An empirical study is currently being conducted to shed more light on how access conditions are applied in practice. Finally, we conclude that a complete harmonization might be neither desirable, nor feasible, considering the different nature of biobank initiatives and the different legal frameworks applicable to these initiatives. ${ }^{7}$

\section{Acknowledgments}

The comparative analysis is part of a $\mathrm{PhD}$ project funded by the Agency for Innovation by Science and Technology in Flanders (Belgium) (IWT). The content is solely the responsibility of the authors and does not necessarily represent the official views of the IWT. Preliminary data have been presented at the ESBB inaugural conference in Marseille (France) from November 16-19, 2011 $1^{41}$ and at the 'HandsOn Biobanks' Conference in Uppsala (Sweden) on September 21, 2012.

\section{Author Disclosure Statement}

No competing financial interests exist.

\section{References}

1. Cadigan RJ, Easter MM, Dobson AW, et al. "That's a good question": University researchers' views on ownership and retention of human genetic specimens. Genet Med 2011; 13:569-575.

2. Fortin S, Pathmasiri S, Grintuch R, et al. "Access arrangements" for biobanks: A fine line between facilitating and hindering collaboration. Public Health Genomics. 2011; 14:104-114.

3. Edwards T, Cadigan RJ, Evans JP, et al. Biobanks containing clinical specimens: Defining characteristics, policies, and practices. Clin Biochem 2014;47:245-251.

4. Access to collections of data and materials for health research: A report to the Medical Research Council and the Wellcome Trust [Internet]. Medical Research Council and the Wellcome Trust; 2006. Available from: http://www .wellcome.ac.uk/About-us/Publications/Reports/Biomedicalethics/WTX030843.htm. Last accessed December 2, 2014.

5. Knoppers BM, Chisholm RL, Kaye J, et al. A P3G generic access agreement for population genomic studies. Nat Biotechnol 2013;31:384-385.
6. Zatloukal K, Vaught J. What are the next steps to overcoming roadblocks to transnational biobank collaboration? Biopreserv Biobank 2012];10:2-3.

7. Morente MM, Cereceda L, Luna-Crespo F, et al. Managing a biobank network. Biopreserv Biobank 2011;9: 187-90.

8. Scott CT, Caulfield T, Borgelt E, et al. Personal medicineThe new banking crisis. Nat Biotechnol 2012;30:141-147.

9. Watson PH, Ravid R, Eng CB, et al. What are the main roadblocks to transnational biobank collaboration, and how can we overcome them? Biopreserv Biobank 2011;9:213216.

10. Lopez-Guerrero JA, Riegman PHJ, Oosterhuis JW, et al. TuBaFrost 4: Access rules and incentives for a European tumour bank. Eur J Cancer 2006;42:2924-2929.

11. Lemrow SM, Colditz GA, Vaught JB, et al. Key elements of access policies for biorepositories associated with population science research. Cancer Epidemiol Biomarkers Prev 2007;16:1533-1535.

12. Vaught J, Kelly A, Hewitt R. A review of international biobanks and networks: Success factors and key benchmarks. Biopreserv Biobank 2009;7:143-150.

13. Joly Y, Zeps N, Knoppers BM. Genomic databases access agreements: Legal validity and possible sanctions. $\underline{\text { Hum }}$ Genet 2011;130:441-449.

14. $\overline{\mathrm{P} 3 \mathrm{G}}$ Sample and data Access Policy: Core Elements [Internet]. P3G; 2008. Available from: http://www.p3g.org/ biobank-toolkit/p3g-sample-and-data-access-core-elements

15. Creation and Governance of Human Genetic Research Databases [Internet]. OECD; 2006. Available from: http:// www.oecd.org/science/biotech/creationandgovernanceof humangeneticresearchdatabases.htm. Last accessed December 2, 2014.

16. Colledge F, Elger B, Howard HC. A review of the barriers to sharing in biobanking. Biopreserv Biobank 2013;11: 339-346.

17. Campbell LD, Betsou F, Garcia DL, et al. Development of the ISBER best practices for repositories: collection, storage, retrieval and distribution of biological materials for research. Biopreserv Biobank 2012;10:232-233.

18. Hens K, Nys H, Cassiman J-J, et al. Biological sample collections from minors for genetic research: A systematic review of guidelines and position papers. Eur J Hum Genet 2009;17:979-990.

19. Cambon-Thomsen A, Rial-Sebbag E, Knoppers BM. Trends in ethical and legal frameworks for the use of human biobanks. Eur Respir J 2007;30:373-382.

20. Bauer K, Taub S, Parsi K. Ethical issues in tissue banking for research: A brief review of existing organizational policies. Theor Med Bioeth 2004;25:113-142.

21. Master Z, Nelson E, Murdoch B, et al. Biobanks, consent and claims of consensus. Nat Methods 2012;9:885-888.

22. Henderson GE, Edwards TP, Cadigan RJ, et al. Stewardship practice of U.S. biobanks. Sci Transl Med 2013;5:1-6.

23. Crawford G, Foulds N, Fenwick A, et al. Genetic medicine and incidental findings: It is more complicated than deciding whether to disclose or not. Genet Med 2013;15:896-899.

24. Principles and Guidelines for Access to Research Data from Public Funding [Internet]. OECD; 2007. Available from: http://www.oecd.org/science/sci-tech/38500813.pdf. Last accessed December 2, 2014.

25. Yassin R, Lockhart N, González del Riego M, et al. Custodianship as an ethical framework for biospecimen-based research. Cancer Epidemiol Biomarkers Prev 2010;19: 1012-1015. 
26. NCI Best Practices for Biospecimen Resources. 2011. Available from: http://biospecimens.cancer.gov/bestpractices/ 2011-NCIBestPractices.pdf. Last accessed December 2, 2014.

27. Material and Data Access Agreement- Core Elements and Generic Clauses [Internet]. P3G; 2008 p. 6. Available from: http://www.p3gobservatory.org/repository/ethics.htm. Last accessed June 10, 2014.

28. Wichmann H-E, Kuhn K, Waldenberger M, et al. Comprehensive catalog of European biobanks. Nat Biotechnol 2011;29:795-797.

29. Human biobanks for research: Opinion [Internet]. Berlin: Deutscher Ethikrat; 2010. Available from: http://www .ethikrat.org/dateien/pdf/stellungnahme-humanbiobankenfuer-die-forschung.pdf. Last accessed December 2, 2014.

30. Zika E, Paci D, Schulte in den Bäumen T, et al. Biobanks in Europe: Prospects for Harmonisation and Networking. 2010 p. 170. Available from: http://ipts.jrc.ec.europa.eu/ publications/pub.cfm?id=3259. Last accessed December 2, 2014.

31. Riegman PHJ, Morente MM, Betsou F, et al. Biobanking for better healthcare. Mol Oncol 2008;2:213-222.

32. Asslaber M, Zatloukal K. Biobanks: Transnational, European and global networks. Brief Funct Genomic Proteomic 2007;6:193-201.

33. Watson RWG, Kay EW, Smith D. Integrating biobanks: Addressing the practical and ethical issues to deliver a valuable tool for cancer research. Nat Rev Cancer 2010;10: 646-651.

34. O'Brien SJ. Stewardship of human biospecimens, DNA, genotype, and clinical data in the GWAS era. Annu Rev Genomics Hum Genet 2009;10:193-209.
35. Hakimian R, Korn D. Ownership and use of tissue specimens for research. JAMA 2004;292:2500-2505.

36. All for one and one for all. Nat Methods 2009;6:111.

37. Quigley M. Property and the body: Applying Honore. J Med Ethics 2007;33:631-634.

38. Björkman B. Different types-different rights. Distinguishing between different perspectives on ownership of biological material. Sci Eng Ethics 2007;13:221-233.

39. Samples and data for research: Template for access policy development [Internet]. National Cancer Research Institute, the National Cancer Intelligence Network and onCorde UK; 2009 p. 45. Available from: http://www.ncri.org.uk/ wp-content/uploads/2013/09/Initiatives-Biobanking-2-Accesstemplate.pdf. Last accessed December 2, 2014.

40. Vaught J, Lockhart NC. The evolution of biobanking best practices. Clin Chim Acta 2012;413:1569-1575.

41. Verlinden M, Ectors $\mathrm{N}, \mathrm{Nys} \mathrm{H}$, et al. Access rules within biobanks networks. Biopreserv Biobank 2011;9:304.

Address correspondence to: Dr. Michiel Verlinden Clinical Pharmacology and Pharmacotherapy KU Leuven Herestraat 49, Box 521 3000 Leuven Belgium

E-mail: Michiel.Verlinden@pharm.kuleuven.be 